\title{
SATELLITE BASED REMOTE SENSING TECHNIQUE AS A TOOL FOR REAL TIME MONITORING OF LEAF RETENTION IN NATURAL RUBBER PLANTATIONS AFFECTED BY ABNORMAL LEAF FALL DISEASE
}

\author{
B. Pradeep ${ }^{\text {a, } *, \text { S. Meti }}{ }^{\text {b }}$ J. James ${ }^{\text {a }}$ \\ ${ }^{a}$ Rubber Research Institute of India, \\ Rubber Board, Ministry of Commerce \& Industry, Govt. of India \\ Kottayam 686009 , Kerala, India - (pradeep, james)@ rubberboard.org.in \\ ${ }^{\mathrm{b}}$ University of Horticulture Science \\ Udyanagiri, Bagalkot 587 103, Karnataka, India - \\ shankarmeti@gmail.com
}

KEY WORDS: Abnormal Leaf Fall, Leaf Area Index, MODIS, Natural Rubber, Refoliation, Remote Sensing, Rubber yield

\begin{abstract}
:
Most parts of the traditional natural rubber growing regions of India, extending from Kanyakumari district of Tamil Nadu in the South to Kasaragod district of Kerala in the North received excess and prolonged rains during 2013. This led to severe incidence of Abnormal Leaf Fall (ALF) disease caused by the fungus, Phytophthora sp. The present study demonstrated the first time use of satellite remote sensing technique to monitor ALF disease by estimating Leaf Area Index (LAI) in natural rubber holdings in near real time. Leaf retention was monitored in between April and December 2012 and 2013 by estimating LAI using MODIS 15A2 product covering rubber holdings spread across all districts in the traditional rubber growing region of the country that was mapped using Resourcesat LISS III 2012 and 2013 data. It was found that as the monsoon advanced, LAI decreased substantially in both years, but the reduction was much more substantial and prolonged in many districts during 2013 than 2012 reflecting increased leaf fall due to ALF disease in 2013. The decline was more pronounced in central and northern Kerala than in the South. Kanyakumari district of Tamil Nadu is generally known to be free from ALF disease, but there was considerable leaf loss due to ALF in June 2012 and June and July 2013 even as the monsoon was unusually severe in 2013. Weighted mean LAI during for the entire period of April to December was estimated as a weighted average of LAI and per cent of total area under rubber in each district in the study area for the two years. This was markedly less in 2013 than 2012. The implications of poor leaf retention for biomass production (net primary productivity), carbon sequestration and rubber yield are discussed.
\end{abstract}

\section{INTRODUCTION}

Almost 90 per cent of India's natural rubber is produced from the traditional rubber growing region that stretches from Kanyakumari in the South to Kasaragodu in the North (IRS, 2012). This part of the country has been witnessing marked rise in temperature in recent years and decades (Jacob and Satheesh, 2010; Raj et al., 2011; Satheesh, 2014). Earlier analyses have shown that for a unit concomitant rise in maximum and minimum temperatures, productivity of natural rubber can be reduced by almost 9-16 per cent here. However, in North East India, climate warming will have little inhibitory effect on rubber yield, if not a likely stimulation (Satheesh and Jacob, 2011; Satheesh, 2014). Since North East India supplies only 4 per cent of the country's total natural rubber, climate warming in this part of the country will not have any significant immediate impact on total natural rubber production in the country. On the contrary, warming conditions in traditional regions where bulk of the natural rubber in India is produced can have immediate negative impact on the total rubber production in India (Satheesh, 2014).

Climate change can pose serious challenges to natural rubber production in India (Satheesh, 2014). Impact of climate change on natural rubber is not limited to the direct inhibitory effect of climate warming on rubber yield which can be substantial in the traditional rubber growing regions (Satheesh and Jacob, 2011). More complex and difficult to predict than the effects of climate warming are changes associated with cloud formation, rainfall distribution, occurrence of extreme weather events etc. and their impacts on incidence of pests and diseases which can have direct or indirect effects on growth and productivity of natural rubber. The year 2013 witnessed unusually intense and prolonged monsoon leading to serious outbreak of Abnormal Leaf Fall (ALF) disease resulting in extensive leaf loss for most part of

\footnotetext{
* Corresponding author. pradeep@ rubberboard.org.in
} 
the year. In the present study, we made use of satellite data to estimate leaf retention in real time by estimating Leaf Area Index (LAI) in rubber holdings in the different districts in the traditional rubber growing region of India from April to December 2012 and 2013. The technique described in this study gives us the ability for remotely monitoring LAI in rubber holdings in any part of the world at any time (provided good quality satellite data are available). Implications of LAI for primary productivity and likely impact of poor leaf retention during 2013 on rubber yield are discussed.

\section{MATERIALS \& METHODS}

Administrative boundary of the study area was vectorized using georeferenced Survey of India toposheets of scale 1:2,50,000. Ortho-rectified IRS P6 LISS III scenes covering Kerala and Kaniyakumari district were used for the delineation of rubber area (Table 1). Satellite acquisition dates were selected corresponding to maximum foliage period of rubber (February-March). Rubber being deciduous sheds leaf and refoliate immediately whereas other deciduous trees do not. Hence rubber during this period shows distinct spectral signature particularly in infrared band compared to other vegetation. District-wise satellite images were classified using $\mathrm{K}$ means clustering (minimum distance) algorithm. Spatial distribution map was prepared using the ground information, GPS readings of major vegetation classes and unique spectral signature of rubber. Geographical location readings (Garmin Oregon 550) of rubber and dominant vegetation classes in each district were used as test point for accuracy assessment of classified image.

\begin{tabular}{|c|c|c|c|}
\hline \multirow{15}{*}{ 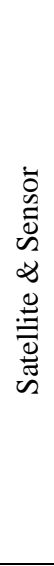 } & \multirow{15}{*}{ 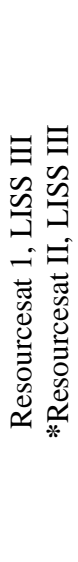 } & Date of acquisition & Path-Row \\
\hline & & $3^{\text {rd }}$ Mar. 2013 (*R II) & $100-67$ \\
\hline & & $25^{\text {th }}$ Mar. 2012 & $101-68$ \\
\hline & & $25^{\text {th }}$ Feb. 2012 & $100-68$ \\
\hline & & $20^{\text {th }}$ Feb. 2012 & $99-67$ \\
\hline & & $20^{\text {th }}$ Feb. 2012 & $99-66$ \\
\hline & & $20^{\text {th }}$ Feb. 2012 & $99-65$ \\
\hline & & $5^{\text {th }}$ Mar. 2013 & $98-65$ \\
\hline & & $5^{\text {th }}$ Mar. 2013 & $98-64$ \\
\hline & & $29^{\text {th }}$ Mar.2013 & $98-63$ \\
\hline & & $28^{\text {th }}$ Feb.2013 & $97-64$ \\
\hline & & $24^{\text {th }}$ Mar. 2013 & $97-63$ \\
\hline & & $2^{\text {nd }}$ Mar. 2011 & $100-67$ \\
\hline & & $1^{\text {st }}$ Feb. 2011 & $99-67$ \\
\hline & & $1^{\text {st }}$ Feb. 2011 & $99-66$ \\
\hline
\end{tabular}

Table 1. Details of the satellite data used for rubber area distribution mapping

Prior to satellite based LAI estimation of rubber holdings, LAI field measurements were taken from rubber holdings during defoliation (Deecmber- January), refoliation (MarchApril) and ALF disease (June- July) seasons using Sunscan Canopy Alanyzer SS1. MODIS Terra satellite data was used for LAI estimation. MODIS $1 \mathrm{~km}$ LAI tile data (MOD15A2) covering the study area (Kanyakumari district of Tamil Nadu in the South to Kasaragod district of Kerala in the North) for the period April to December 2012 and 2013 were downloaded from the USGS site (http://glovis.usgs.gov). MODIS Hierarchical Data Format (HDF) was converted using MODIS tool. All tiles were reprojected and mosaicked using Geomatica v 10.3.1 image processing software. The study area was clipped and scale factor $(0.1)$ was applied to MODIS data sets for generating LAI values. No data values were removed from MODIS tiles and quality of LAI data was assessed using quality flag parameters. Uniform rubber area distribution map was overlaid over the MODIS LAI image and selected rubber area covering the 75 per cent of the pixel area of MODIS data with point. This point data file was overlaid over LAI raster image and extracted the LAI quality parameters. Then district-wise monthly mean LAI values were calculated. LAI during April/May coincides with the phenological stage of refoliated mature leaves (maximum foliage retention) and normally, June/July coincided with peak incidence of abnormal leaf fall disease (least foliage retention). During 2013, monsoon was prolonged causing serious defoliation due to ALF in several districts which was monitored using monthly LAI data from April to December 2013 and compared with the LAI data for the same period in 2012 when the monsoon was much less aggressive. A weighted mean LAI for the entire period of April to December was calculated for 2012 and 2013. This was done by multiplying the mean LAI for each district for the year with the per cent of total area under rubber in the respective district. This ensured that LAI for each district had different weightage according to the extent of rubber area in each district.

\section{RESULTS AND DISCUSSION}

Spatial distribution of rubber growing areas of Kerala and Kanyakumari district of Tamil Nadu is given in Figure 1. Overall accuracy of the satellite image classification was 89.7 per cent. Total area under rubber in the study area was $5,58,599$ ha. LAI is the ratio of leaf area per unit land area or the number of layers of leaves present above the ground (Chen and Black, 1992). LAI has a direct bearing on light interception by the canopy and biomass productivity in any crop (Tianxiang et al., 2002; Heiskanen, 2006). In the present study, we demonstrate for the first time use of satellite-based remote sensing technique as an easy, fast and powerful tool to monitor leaf retention by rubber plantations.

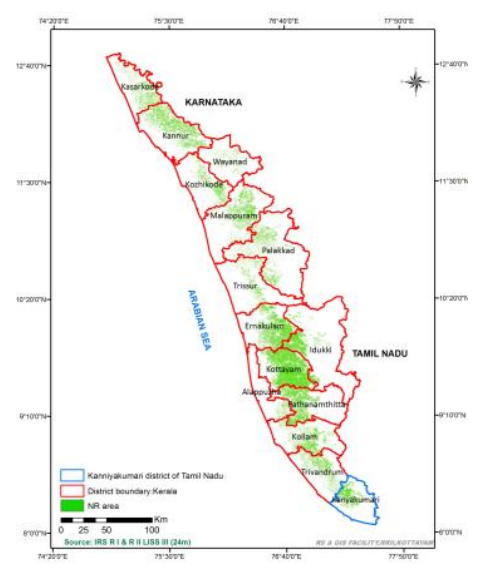

Figure 1. Spatial distribution of rubber growing areas of Kerala and Kanyakumari district of Tamil Nadu

The year 2013 had unusually intense and long monsoon causing severe incidence of ALF disease leading to poor leaf retention for most part of the year after the onset of the rains 
in June compared to 2012 when the monsoon was less intense (Figure 2). Field measurements of time series LAI readings of rubber plantations is shown in Figure 3. Overlay analysis of rubber distribution and LAI showed April/May is the time when LAI is generally high.

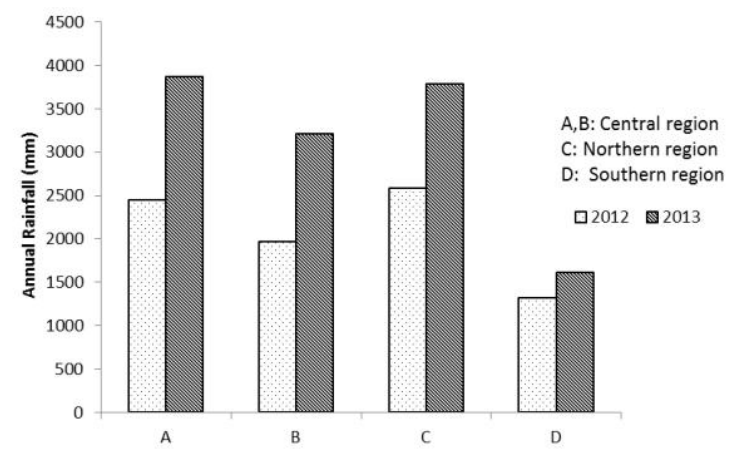

Figure 2. Annual rainfall data for the year 2012 and 2013

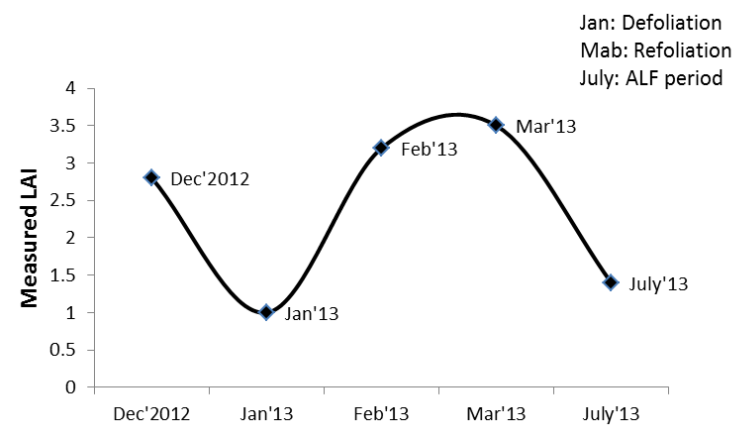

Figure 3. Field measurement of Leaf Area Index (LAI) of natural rubber holdings in different seasons.

This is because after the natural leaf fall in January/February (wintering), the new foliage will be fully formed by March/April. Until the beginning of monsoon in June, there was little difference in LAI among most of the rubbergrowing districts. As the monsoon advanced, there was marked loss of foliage (Figure 4) (as a result of severe incidence of ALF which was corroborated through field reconnaissance of the disease). Even as early as April 2013, LAI was rather poor in Thrissur, Palghat and Malappuram districts suggesting early incidence of ALF. The first sharp decline in LAI was observed in all other districts in July in both years which is the time when monsoon reaches a peak in this part of the country. Thus, variations in LAI were observed across the region and time of the year in both years, but the decline in LAI was more sharp and prolonged during 2013 than 2012 (Figure 4). In general, decline in LAI was quicker, more pronounced and prolonged in the central and Northern parts than in the Southern region. Kanyakumari district maintained better leaf retention throughout most of the study period in both years. It is generally known that ALF incidence is relatively absent in this district compared to the rest of the traditional areas (Mathew et al., 2010). However, due the severity of the monsoon, even in this district there was marked leaf loss due to ALF, albeit for a short period of two months (June and July) during 2013.

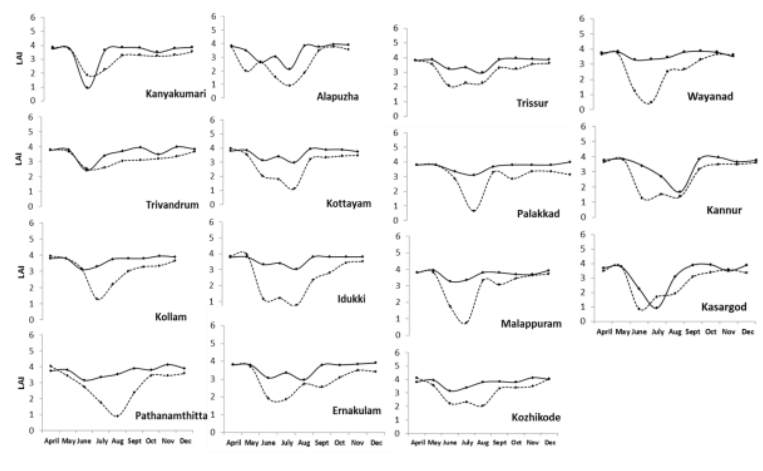

Figure 4. Leaf Area Index (LAI) of NR Plantations of Kerala and Kanyakumari estimated from satellite data during 2012 and 2013

Leaves are the only source where carbohydrates, the precursors for making latex are synthesized in rubber trees. There is a direct and immediate association between current carbohydrate synthesis and yield in annual grain crops such as wheat and rice (Setter et al., 1994; Kumura, 1995; Asseng and Herwaarden, 2003; Xue et al., 2008). However in rubber, the economic yield is not a reproductive organ, located close to the source of production of carbohydrates. Rubber is a secondary metabolite produced through complex and highly specialized biochemical processes in the designated laticiferous cells present in the soft bark tissues far away from the source of carbohydrate production. The relationship between current year's carbohydrate production (which depends on LAI) and that year's rubber yield is difficult to quantify. However, it is only natural that large loss of leaves will markedly reduce rubber yield, but there is no accepted methodology as such to quantify how far reduced leaf retention during 2013 might impact rubber yield.

In the present study, we addressed this issue by giving different weightage to LAI in each district according to the relative extent of area under rubber in each district. LAI varied between months and districts which had different extents of rubber cultivation. The mean LAI that prevailed between April and December (of 2012 and 2013) in a given district was multiplied with the per cent of area cultivated under rubber in the same district to obtain an estimate of the area-weighted LAI in these districts (Figure 5). This ensured that a district with more rubber area had a greater weightage attached to its mean LAI for the period from April to December and vice versa. Thus, districts of Kottayam, Ernakulam and Pathanamthitta which had relatively more share of rubber area also had higher area-weighted LAI. Similarly, districts such as Alapuzha and Idukki which had only very small area under rubber also had small areaweighted LAI (Figure 5). The sum of the area-weighted LAIs from all districts was as high as 358 during April to December 2012. This declined to 293 during the corresponding period in 2013 which is a $22 \%$ reduction from 2012 (Figure 5 inset). It is unlikely that there will be a one-toone correspondence between reduction in the sum of areaweighted LAI and loss in rubber yield. Considering the importance of leaf retention for rubber yield as explained above, it will not be surprising if a substantial extent of loss in area-weighted LAI is reflected as lost yield which we expect could be in the range of $10-15 \%$ reduction in yield in 2013 compared to 2012 . 


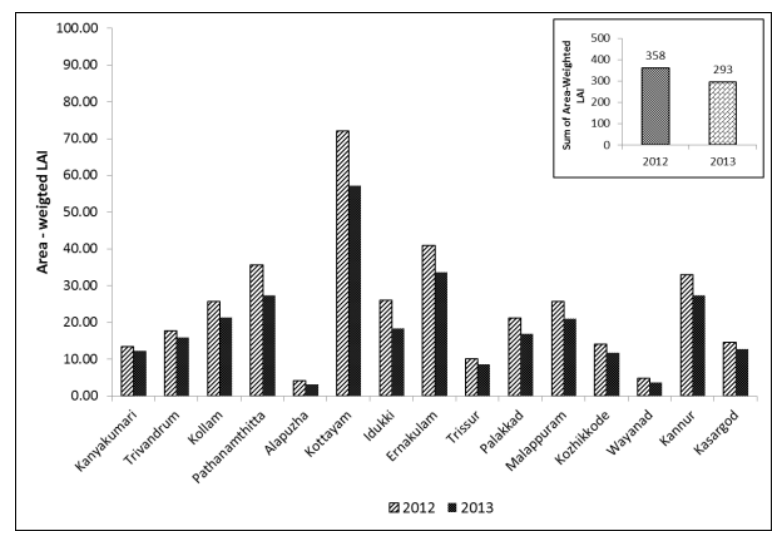

Figure 5. Area-weighted LAI between April and December in different districts during 2012 and 2013. Sum of Areaweighted LAI for the same period is given in the inset.

\section{CONCLUSION}

The study shows the utility of MODIS terra satellite data for monitoring LAI of rubber plantations in different seasons and correlated the declining trend of LAI in monsoon season with ALF disease of rubber plantations. LAI, amount of light intercepted by the canopy and efficiency of conversion of absorbed light into biomass are the major determinants of net primary productivity (Luo, 1996; Hirose et al., 1997; Luo et al., 2004) which results in net sequestration of $\mathrm{CO}_{2}$ from the atmosphere. Net primary productivity in terms of biomass production (or $\mathrm{CO}_{2}$ sequestration) is an important trait determining the yield of a rubber tree, because the larger the trunk size, the longer the tapping cut and thus the more the latex yield in a given clone (Sethuraj, 1981). Studies are on to monitor LAI using satellite-based remote sensing techniques and relate the same to net primary productivity (biomass production and $\mathrm{CO}_{2}$ sequestration) and rubber yield with the ultimate objective of predicting potential rubber production in different rubber growing countries using satellite-based LAI data.

\section{REFERENCES}

Asseng, S. and Herwaarden A.F.V. 2003. Analysis of the benefits to wheat yield from assimilates stored prior to grain filling in a range of environments. Plant Soil, 256, pp. 217229.

Chen, J. M. and Black, T. A. 1992. Defining Leaf Area Index for non-flat leaves. Plant Cell and Environment. 15, pp. 421429.

Heiskanen, J., 2006. Estimating aboveground tree biomass and leaf area index in a mountain birch forest using ASTER satellite data. International Journal of Remote Sensing, 27 (6), pp. 1135-1158.

Hirose, T., Ackerly, D.D., Traw, M.B., Ramseier, D. and Bazzaz, F.A. 1997. CO2 elevation, canopy photosynthesis and optimal leaf area index. Ecology, 78, pp. 2339-2350.

Indian Rubber Statistics. 2012. Compiled by: Statistics and Planning Department. The Rubber Board, Kerala, Ministry of Commerce \& Industry, Govt. of India. 34: 7-8.
Jacob, J and Satheesh, P.R. 2010. Impact of climate change on natural rubber productivity in different agro-climatic regions in India. International workshop on climate change and rubber cultivation: R \& D priorities. Rubber Research Institute of India, Kottayam-686 009, India.

Kumura, A., 1995. Physiology of high yielding rice plants from the viewpoint of dry matter production and its partitioning. In: Matsuo, M. et al., eds. Science of the rice plant, Food Agriculture Policy Research Centre, Tokyo, Japan, 2: 704-736.

Luo, T., 1996. Pattern of net primary productivity for Chinese major forest types and their mathematical models. Ph.D. thesis. Commission for Integrated survey of Natural resources, Chinese Academy of Sciences, Beijing, China.

Luo, T., Pan, Y., Ouyang, H., Shi, P., Lou, J., Yu, Z. and Lu, Q. 2004. Leaf area index and net primary productivity along subtropical to alpine gradients in the Tibetan plateau. Global Ecology and Biogeography, 13, pp. 345-358.

Mathew, J., Abraham, T., Jose, V. T., Mondal, G.C., Raj, S., and Sailajadevi, T. 2010. Prevalence of pests and diseases of Hevea brasiliensis in India - past and present. International workshop on climate change and rubber cultivation: R \& D priorities. Rubber Research Institute of India, Kottayam, India.

NMCE., 2012. National Multi Commodity Exchange, Natural Rubber. pp. 3-23.

Raj, S., Satheesh, P.R., and Jacob, J. 2011. Evidence for climate warming in some natural rubber growing regions of south India. Natural Rubber Research, 24 (1), pp. 10-17.

RRII., 2014. Satellite survey of Natural rubber plantations in Kerala, Tamil Nadu and Karnataka. Consultancy project for Automative Tyre Maufacturers' Association (ATMA), New Delhi. Rubber Board, Kottayam, Kerala.

Satheesh, P.R., 2014. Ph.D. Thesis. Impact of climate change on Indian plantation sector with special reference to natural rubber. Submitted to Mahatma Gandhi University, Kottayam, Kerala.

Satheesh, P.R. and Jacob, J. 2011. Impact of climate warming on natural rubber productivity in different agro-climatic regions of India. Natural Rubber Research, 24 (1), pp. 1-9.

Setter, T.L., Peng, S., Kirk, G.J.D., Virmani, S.S., Kropff, M.J. and Kasman, K.G. 1994. Physiological consideration and hybrid rice. Proceedings on rice yield potential in favourable environments, IRRI. pp. 39-57

Sethuraj, M. R. 1981. Yield components in Hevea brasiliensis. Plant Cell and Environment, 4, pp. 81-83.

Tianxiang, L., Ronald, N.P., Hanqin, T., Charles, V.J., Huazhong, $Z$ and Shirong, L. 2002. A model for seasonality and distribution of leaf area index of forests and its application to China. Journal of Vegetation Science, 13, pp. 817-830.

Xue, G.P., McIntyre, C.L., Jenkins, C.L.D., Glassop, D., Herwaarden A.F.V. and Shorter, R. (2008). Molecular 
The International Archives of the Photogrammetry, Remote Sensing and Spatial Information Sciences, Volume XL-8, 2014 ISPRS Technical Commission VIII Symposium, 09 - 12 December 2014, Hyderabad, India

dissection of variation in carbohydrate metabolism related to water soluble carbohydrate accumulation in stems of wheat (Triticum aestivam L.). Plant Physiology, 146, pp. 441-454. 